\title{
Quaderni
}

QUADERNI Communication, technologies, pouvoir

$67 \mid$ Automne 2008

Jeu vidéo et discours

\section{Communication politique autour d'une culture identitaire et fédératrice}

Les festivals hip hop organisés dans les villes de banlieue

\section{Laurent Béru}

\section{(2) OpenEdition}

\section{Journals}

Édition électronique

URL : http://journals.openedition.org/quaderni/232

DOI : 10.4000 /quaderni.232

ISSN : 2105-2956

Éditeur

Les éditions de la Maison des sciences de l'Homme

Édition imprimée

Date de publication : 5 octobre 2008

Pagination : 93-99

\section{Référence électronique}

Laurent Béru, «Communication politique autour d'une culture identitaire et fédératrice », Quaderni [En ligne], 67 | Automne 2008, mis en ligne le 05 janvier 2012, consulté le 19 avril 2019. URL : http:// journals.openedition.org/quaderni/232; DOI : 10.4000/quaderni.232 


\section{Communication}

communication politique autour d'une culture identitaire et fédératrice les festivals hip hop organisés dans les villes de banlieue

\section{Laurent Béru}

Université Sorbonne Nouvelle Paris III
Pour les collectivités territoriales, communiquer est une activité capitale ${ }^{1}$. Dans une ville comme Saint-Denis, inclure le mouvement hip hop en tant qu'expression patrimoniale au sein du patrimoine culturel représentatif des quartiers populaires dionysiens, et cela au même titre que le patrimoine monumental dionysien qui intervient comme emblème historique de cette commune de la banlieue parisienne ${ }^{2}$, c'est rompre avec les images inquiétantes diffusées par les médias et les discours alarmistes des gouvernants. L'objectif affiché est de promouvoir le dynamisme et la créativité de la ville. En effet, hormis le Fonds d'action sociale (FAS) ou la Direction régionale des affaires culturelles (DRAC), les villes de la banlieue populaire de Paris (Aubervilliers, Noisy-le-Sec...) ou de Lyon (Vaulx-en-Velin, Vénissieux...) s'investissent pleinement dans la promotion des activités culturelles et artistiques générées sur leur territoire par les forces vives de leur population - que ce soit les animateurs de quartier, les organisateurs de manifestations événementielles, les artistes amateurs ou professionnels. Cependant, il peut paraître curieux que le hip hop, mouvement culturel souvent perçu comme marginal et dissident (c'est-à-dire dont la pratique originelle se désolidarise des lieux et des pouvoirs institutionnels pour développer une forme d'expression jugée pour le moins « hors-la-loi » par l'establishment), soit annexé et soutenu par les institutions municipales, départementales, régionales et/ou nationales. En effet, quand graffeurs et tagueurs sont poursuivis en justice par la RATP, et condamnés par les tribunaux à des peines d'amende et/ou à des travaux d'intérêt général ${ }^{3}$, et que des rappeurs sont accusés par certains élus de prêcher la haine raciale et d'inciter à la violence physique ${ }^{4}$, dans le 
même temps, des maires et des ministres mettent en valeur cette culture rebelle, souvent stigmatisée pour son caractère à la limite de l'illicite. Ce fut le cas de Bertrand Delanoë, actuel maire de Paris, qui a facilité la création de la Maison du hip hop, et de Renaud Donnedieu de Vabres, ancien ministre de la Culture, qui a encouragé la tenue de la manifestation artistique Rue $\mathrm{Au}$ Grand Palais. Dans le cadre de cette étude, nous privilégierons le cas des départements franciliens, en prenant particulièrement l'exemple de la Seine-Saint-Denis.

\section{Identification départementale et régionale : quand le territoire produit des pratiques artistico-culturelles emblématiques}

Le chant, la musique et la danse sont des produits culturels originellement ancrés au sein d'un territoire donné : en effet, une ville ou une région peut représenter une culture artistique précise, et en être le «fief » territorial du point de vue national, continental ou mondial. Par exemple, certaines villes autrichiennes (Vienne, Salzbourg...) sont reconnues pour avoir vu naître les œuvres de compositeurs célèbres (Johann Strauss, Joseph Haydn, Wolfgang Mozart...) et abrité des salles de concert mythiques dédiées à la musique classique (Staatsoper Wien, Salzburger Marionettentheater...), mais aussi pour avoir favorisé l'institutionnalisation de la valse. C'est également le cas, en Espagne, de la musique et de la danse flamencas, fortement liées et généralement identifiées dans la conscience collective à la région andalouse (et notamment à des villes comme Séville ou Jerez). En France, dans la banlieue parisienne, certaines petites salles sont de hauts lieux des cultures musicales alternatives (rap, reggae, rock...) et d'importants espaces de rencontre pour leurs initiés : citons le cas de deux petites salles de concert de Seine-Saint-Denis, le Café La Pêche (Montreuil) et la Ligne 13 (Saint-Denis). L'ancrage spatioculturel du rap au sein des territoires de la banlieue populaire d'Îlede-France s'est affirmé à partir de l'émulation entre artistes locaux et de l'intérêt grandissant des spectateurs-auditeurs locaux, mais également grâce aux choix sélectifs de la politique culturelle des municipalités et des subventions institutionnelles qui suivirent. Pour ce qui est du rap, de tels choix de subventions ont permis et permettent, entre autres, à de jeunes artistes amateurs ou (semi-)professionnels de répéter dans des locaux adaptés, réaliser des maquettes ou encore faire des concerts.

En effet, au moment d'arrêter les grandes lignes de leur politique culturelle, les collectivités territoriales prennent souvent en compte les particularités culturelles historiques de leur région. Lors de l'attribution de subventions, elles font grand cas des projets qui mettent en valeur les richesses humaines et socioculturelles du territoire administré. Ainsi, tant dans l'objectif de s'assurer le concours financier des collectivités territoriales que dans la volonté d'enraciner leur manifestation dans un des «bastions» de la musique et/ou de la danse qu'ils veulent valoriser, les organisateurs de festivals culturels préfèrent fixer les festivités à programmer dans une ou la région emblématique des pratiques culturelles qu'ils désirent mettre sur scène. De là, par exemple, quand le Sud-ouest est plutôt connu pour être une terre propice à l'organisation de ferias et autres fiestas animées par les déambulations musicales des bandas 
- le Festibandas 64 à Baudreix (PyrénéesAtlantiques) ou le Festival Européen de Bandas à Condom (Gers) -, la Bretagne, quant à elle, est davantage reconnue pour être le lieu idéal pour la tenue de festoù-noz et festoù-diez égayés de danses, chants et musiques celtiques - le Festival Interceltique de Lorient (Morbihan) ou le Festival de Cornouaille à Quimper (Finistère). Cependant, nous pouvons relever quelques cas notables, où la culture diffusée par un festival est différente de celle de la région hôte - citons le Festival de Mirande, qui « exporte » chaque année dans le Gers la country-music et la western-dance, originaires des États-Unis.

Les élus locaux et les collectivités locales ont une voix prépondérante - par rapport à celle de l'État - dans l'apport du soutien financier effectif en faveur d'un festival culturel. Les collectivités locales subventionnent en priorité les projets socioculturels - que ce soit au niveau de l'organisation d'un festival, la production d'un album ou même la réalisation d'un vidéo-clip - qui œuvrent pour la promotion d'une ville, d'un département, d'une région : des retombées positives en terme d'images sont attendues ${ }^{5}$. Par le passé, dans certaines communes de la banlieue populaire de Paris ou de Lyon, là où la concentration de problèmes sociaux était considérable, l'aide à la création, dont l'objectif premier est d'abord et avant tout le soutien aux artistes et aux pratiques artistiques, s'est souvent confondue avec l'action sociale, et cela dans le but de venir en aide à des familles disposant de trop peu de moyens financiers pour permettre à leurs enfants de se distraire et se cultiver régulièrement. Mais, aujourd'hui, en ce qui concerne la danse hip hop, grâce à la renommée (inter)nationale glanée par de nombreuses compagnies de danse (Black Blanc Beur, Fantastik Armada, Wanted Posse...), quand aides il y a, celles-ci scellent de plus en plus de véritables partenariats entre des artistes (semi-)professionnels et des responsables politiques engagés à soutenir leur démarche artistique en instaurant une sorte de parrainant - souvent, en contrepartie, les bénéficiaires doivent s'engager au niveau associatif.

Ainsi, par exemple, la Compagnie Trafic de Style, qui s'est notamment produite en décembre 2006 lors de la dixième édition du Festival de danse hip hop $\mathrm{H}^{2} \mathrm{O}$ d'Aulnay-sous-Bois, est soutenue par diverses institutions locales : elle bénéficie des subventions du Conseil général de SeineSaint-Denis, du Conseil général du Val-d'Oise et de la Direction régionale des affaires culturelles d'Île-de-France. Autre exemple : la Compagnie Aktuel Force, créée en 1984, en résidence dans la ville de La Villette depuis la fin de l'année 2006 , et présentant ses productions dans divers salles de spectacle de France mais surtout de Seine-Saint-Denis, est subventionnée par la ville de Stains et l'Office municipal de la jeunesse d'Aubervilliers.

\section{La banlieue comme " terroir " des festivals hip hop : une assignation spatiale des arts dits urbains}

L'enracinement du hip hop dans les zones urbaines défavorisées est aussi prégnant que son appropriation par les minorités ethnoraciales socialement stigmatisées - maghrébines (algérienne, tunisienne...) ou subsahariennes (malienne, congolaise...). Pour un rappeur ou un disque-jockey, un tagueur ou un graffeur, se 
revendiquer de tels lieux populaires permet de jouir d'une légitimité sociospatiale et socioculturelle, tant auprès du public que des médias; mais cette revendication est également vraie pour les villes dont les personnalités contemporaines marquantes sont surtout des artistes de hip hop. Concernant ce point, le cas de Saint-Denis est exemplaire : lors des années 1985-1995, la commune attira non seulement de nombreux protagonistes départementaux du hip hop, mais aussi ceux originaires de Paris intra-muros et des autres départements franciliens - le campus de l'Université Paris 8 Saint-Denis a accueilli de nombreux événements (ateliers, conférences-débats, performances, concerts...) dédiés au rap ou au tag. Il est intéressant de constater que dans les villes de la banlieue parisienne, l'apprentissage des diverses disciplines du hip hop - expressions vocale et sonore, mais aussi expressions corporelle et visuelle - représente une part non négligeable des ateliers proposés au sein des maisons des jeunes et de la culture (MJC) - les activités de ces dernières étant subventionnées par les municipalités. Au-delà des stéréotypes, nous pouvons reconnaître l'existence d'une logique socioculturelle selon laquelle certains instruments à musique, certains genres musicaux ou certaines danses sont « assignés » à des territoires précis, car représentatifs des lieux et des goûts de leur population. Ainsi, au même titre que la diffusion de la musique celtique, l'initiation à la cornemuse et la pratique de l'hanterdro symbolisent la culture traditionnelle de certains villages bretons, la diffusion de la musique rap, l'initiation au sampler et la pratique du breakdance évoquent une culture propre aux cités de banlieue ${ }^{6}$.

L'événement national que fut la manifestation artistique Rue Au Grand Palais (13-15 octobre 2006) a démontré que l'organisation d'une telle manifestation pouvait remplacer un discours et une réponse politiques à destination de la population des quartiers défavorisés. Si elle a œuvré en faveur de l'acceptation de la culture hip hop au sein de la « famille » des beaux-arts français, cette manifestation a réaffirmé ce que Jacques Chirac affirmait, un an plus tôt, durant et après l'épisode dramatique médiatiquement nommé « émeutes urbaines $»^{7}$. Dans la perspective d'animer et promouvoir l'identité de l'espace dont ils ont la charge, les responsables municipaux des banlieues populaires des grandes agglomérations françaises, et principalement les maires-adjoints chargés de la politique culturelle et patrimoniale, tendent à s'appuyer sur le dynamisme socioculturel et la pluralité ethnoraciale des quartiers populaires de banlieue - il est à souligner que le hip hop français s'inspire des diverses cultures présentes sur les territoires urbains. De ce fait, il n'est pas étonnant de s'apercevoir que dans plusieurs villes de la banlieue parisienne, des festivals à la gloire du hip hop s'organisent régulièrement, voire même s'installent de manière pérenne. En effet, terreaux populaires rassemblant de grandes difficultés sociales (concentration de la pauvreté, fort taux de chômage, nombreuses familles monoparentales...) et terres d'origine de nombreux rappeurs emblématiques du hip hop hexagonal-de Sefyu(Aulnay-sous-Bois) etAlibi Montana (La Courneuve) à La Caution (Noisyle-Sec) et Tandem (Aubervilliers) en passant par Casey (Le Blanc-Mesnil) et Fatcap (Bondy) -, les communes de Seine-Saint-Denis jouent et assument la carte identitaire «banlieusarde » qui est accolée à ce mouvement culturel. 
À l'instar de l'engagement politique de la plupart des rappeurs, qui s'obligent à dénoncer les multiples injustices socioéconomiques (soit celles qui créent peu ou prou une société à deux vitesses), les équipes municipales de gauche (communistes ou socialistes) fidèles - ne serait-ce qu'en apparence - à des positionnements socialistes et marxistes en perte de vitesse électoralement au sein des communes de l'ex-banlieue rouge parisienne ${ }^{8}$, évoquent très souvent, chacune avec leur propre sensibilité idéologico-politique, des idées axées sur la lutte des inégalités sociales qui rongent et scindent la société entre dominants bourgeois des classes supérieures et dominés prolétaires des classes subalternes. Par conséquent, si l'idéal révolutionnaire de l'ex-banlieue rouge est moins prégnant au sein des communes franciliennes populaires, il n'en demeure pas moins que persistent, ici et là, les vieux souvenirs tenaces des mobilisations de l'anarcho-syndicalisme et des grands mouvements de grève du prolétariat ${ }^{9}$. Quand ils sont amenés à faire un choix entre plusieurs projets culturels susceptibles d'être développés en partenariat avec leur municipalité, des élus de gauche tendent à favoriser ceux qui sont plus ou moins conformes, d'une part, à leur aspirations/influences idéologico-politiques et, d'autre part, aux préférences socioculturelles de leurs administrés. Pour une municipalité de gauche, ne pas soutenir le développement d'un mode d'expression privilégié par les classes populaires, c'est presque inconcevable, voire même politiquement incorrect. D'ailleurs, au début des années 1990, le gouvernement socialiste de l'époque, sous l'impulsion du ministre de la Culture Jack Lang, a plus ou moins ouvertement tenté de « notabiliser » la création artistique des hip hoppers issus des banlieues populaires ${ }^{10}$.
Ainsi, du fait que de nombreux quartiers dits sensibles se trouvent sur le territoire francilien, plusieurs villes des divers départements parisiens s'accordent à mettre en avant la culture hip hop. C'est principalement le cas de la Seine-SaintDenis : par exemple, Saint-Denis et Pantin accueillent respectivement le 93 Hip Hop Festival et le Festival Hip Hop Tanz. Les autres départements parisiens ne sont pas en reste; notons les festivals ponctuels ou récurrents suivants : Vitry Yo ! (à Vitry-sur-Seine, dans le Val-deMarne), Chorégrafzik (au Mée-sur-Seine, dans la Seine-et-Marne), Art'Mature et Alliance Urbaine (le premier à Issy-les-Moulineaux et le second à Bagneux, dans les Hauts-de-Seine), A Baz De Hip Hop et Renc'Art Danses (le premier à Argenteuil et le second à Cergy, dans le Val-d'Oise).

\section{Conclusion}

Ainsi, de manière générale, le hip hop est plus ou moins instrumentalisé par les pouvoirs publics pour « acheter la paix sociale» dans les quartiers dits difficiles; le but est de « canaliser l'énergie négative » de jeunes considérés comme étant 《 en perte de repères $\rangle^{11}$. Très souvent, pour une mairie de banlieue, organiser un festival hip hop, tout comme créer un atelier graff ou rap, c'est offrir aux « laissés-pour-compte » des quartiers défavorisés un divertissement ludique qui peut se substituer à des activités répréhensibles. $\mathrm{Si}$, pour le décideur public, le désir d'apporter l'art et la culture partout et pour tous - c'est-à-dire au sein de chaque lieu et auprès de chaque population - détermine ses choix de subventions publiques, la volonté d'inscrire l'initiation à la pratique de la danse hip hop ou à l'écriture de textes de rap est aussi envisagée dans un objectif éducatif et 
pédagogique. En effet, à partir des valeurs populaires du hip hop, les acteurs publics espèrent promouvoir auprès des jeunes amateurs de hip hop les vertus des cultures artistiques consensuelles, institutionnelles ${ }^{12}$. Par exemple, concernant la danse hip hop, les collectivités territoriales, privilégiant les subventions en faveur de compagnies formelles et au détriment de crews ou posses informels, incitent vivement les artistes locaux à prendre leur distance avec la forme et l'organisation déstructurées des performances underground, afin qu'ils embrassent celles plus structurées des représentations publiques ${ }^{13}$. Ainsi, à l'opposé des battles sportivo-artistiques, qui se déroulaient directement sur la voie publique ou dans les halls d'immeuble, la chorégraphie hip hop est plus que plébiscitée par les décideurs publics, car elle se rapproche de l'esthétisme du ballet.

Avec le bénéfice de la consécration institutionnelle conférée par les médias et de nombreux acteurs des arts dits «nobles » ou " classiques », les diverses disciplines du hip hop sont plus ou moins devenues consensuelles au contact du paysage artistique français. Par exemple, dans le cas de l'expression corporelle du hip hop, la longévité et la renommée internationales de festivals de danses urbaines (comme Suresnes Cités Danse et Rencontres de la Villette), comme l'entrée de danseurs issus de compagnies de danse hip hop dans des projets artistiques institutionnels (notamment lors de la Biennale de la Danse de Lyon), contribuent - toutes proportions gardées - à donner une image positive et attractive du mouvement qui a fait ses débuts dans une certaine marginalité urbaine. Les équipes municipales des banlieues populaires, très souvent consternées par les poncifs qui stigmatisent leurs communes et leurs administrés, se réjouissent de pouvoir profiter de la popularité d'une de leurs richesses socioculturelles : le hip hop. 
$\mathrm{N} \cdot \mathrm{O} \cdot \mathrm{T} \cdot \mathrm{E} \cdot \mathrm{S}$

1. R. Boure, «Quand les collectivités territoriales entrent en communication », in CinémAction, $\mathrm{n}^{\circ}$ 63, printemps 1992, pp. 169-174.

2. Par exemple, la Basilique royale, nécropole des rois de France, ou la Maison d'éducation de la Légion d'honneur, fondée par Napoléon $1^{\mathrm{er}}$.

3. Voir les articles suivants du quotidien Le Monde: «La délinquance dans le métro parisien a enregistré une nette progression en 1987 »(4 mai 1988); «Après les tagueurs, les graveurs lancent un défi à la RATP » (6 juillet 2001).

4. Voir l'article suivant du quotidien Le Monde: «Des parlementaires réclament des poursuites contre des rappeurs » (25 novembre 2005).

5. J. Besançon, Festival de musique: analyse sociologique de la programmationet del'organisation, Paris, L'Harmattan, 2000, pp. 130-141.

6. L. Béru, « La globalité du rap engagé, dissémination d'une logique sociomusicale mondiale », in Colloque Comment la musique vient-elle au territoire?, Bordeaux, Université Michel de Montaigne, 12 mars 2007.

7. L. Béru, «Rue au Grand Palais », in Area Revues, $n^{\circ} 14$, mars 2007, p. 180.

8. P. Subra, « Île-de-France : la fin de la banlieue rouge $»$, in Hérodote, $\mathrm{n}^{\circ} 113$, printemps 2004, pp. 14-27.

9. A. Fourcaut, «Banlieue rouge au-delà du mythe politique », in A. Fourcaut (éd.), Banlieue rouge 19201960 : années Thorez, années Gabin, Paris, Autrement, 1992, pp. 12-37.

10. M. Boucher, Rap, expression des lascars : significations et enjeux du rap dans la société française, Paris, L'Harmattan, 1999, pp. 108-109.

11. M. Boucher, « Hip-hop, gestion des risques et ré- gulation sociale : engagements et dépassements », in M. Boucher \& A. Vulbeau (éds.), Emergences culturelles et jeunesse populaire : turbulences ou médiations, Paris, L'Harmattan, 2003, pp. 276-277.

12. J.-M. Lucas, «Les relations entre les décideurs publics et les musiques amplifiées : un ballet en sept figures », in A. Laffanour (éd.), Territoires de musiques et cultures urbaines : rock, rap, techno... l'émergence de la création musicale à l'heure de la mondialisation, Paris, L'Harmattan, 2003, p. 70.

13. S. Faure, \& M.-C. Garcia, Culture hip hop, jeunes des cités et politiques publiques, Paris, La Dispute, 2005, pp. 15-17 et 58-60. 
